\title{
Article
}

\section{Food security and obesity: Can passerine foraging behavior inform explanations for human weight gain?}

Pool, Ursula

Available at http://clok.uclan.ac.uk/24252/

Pool, Ursula ORCID: 0000-0002-3658-3346 (2019) Food security and obesity: Can passerine foraging behavior inform explanations for human weight gain? Behavioral and Brain Sciences, 42 (E9). ISSN 0140-525X

It is advisable to refer to the publisher's version if you intend to cite from the work. http://dx.doi.org/10.1017/S0140525X18001899

For more information about UCLan's research in this area go to http://www.uclan.ac.uk/researchgroups/ and search for < name of research Group>.

For information about Research generally at UCLan please go to http://www.uclan.ac.uk/research/

All outputs in CLoK are protected by Intellectual Property Rights law, including Copyright law. Copyright, IPR and Moral Rights for the works on this site are retained by the individual authors and/or other copyright owners. Terms and conditions for use of this material are defined in the policies page.

\section{CLoK}

Central Lancashire online Knowledge www.clok.uclan.ac.uk

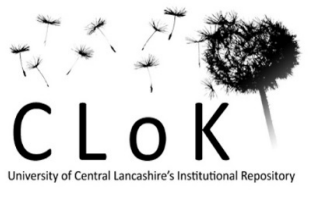


$<\mathrm{CT}>$ Food security and obesity: Can passerine foraging behavior inform explanations for human weight gain?

$<\mathrm{CA}>$ Ursula Pool

$<$ CAA $>$ Healthy \& Sustainable Settings Unit, Faculty of Health \& Wellbeing, University of Central Lancashire, Westlakes Campus, CA24 3JZ, UK.

upool1@uclan.ac.uk

\section{$<$ C-AB $>$ Abstract}

Commonly used measures of human food insecurity differ categorically from measures determining food security in other species. In addition, human foraging behaviors may have arisen in a divergent evolutionary context from non-human foraging. Hence, a theoretical framework based on food insecurity and fat storage in non-humans may not be appropriate for explaining associations between human food insecurity and obesity.

\section{$<$ C-Text begins $>$}

Obesity is rising globally and in all regions of the world (UN Food and Agriculture Organisation [FAO] et al. 2017). However within countries, obesity is unequally distributed, with lower socioeconomic status often associated with higher prevalence of obesity. The inverse social gradient in obesity is not restricted to high-income countries in North America and Europe; it is also found in lower- and middle-income countries across all continents (Popkin \& Gordon-Larsen 2004). Based on associations between food insecurity and high 
body weight, it has been argued that food insecurity could be a causal factor (Nettle et al. 2017). Anselme \& Güntürkün (A\&G) advance a theory compatible with this position, proposing mechanisms that might underlie the relationship between food insecurity and obesity. However, problems arise from the application of their model, based on animal behavior, to a human context.

It cannot be assumed that food security as represented in A\&G's model is equivalent to routine measures of human food security. $A \& G$ use a quantitative measure relating to availability of food in the environment. However, widely used human measures such as the U.S. Department of Agriculture's Household Security Survey Module (Nord et al. 2009) require individuals to assess their qualitative experiences of having enough food to eat, as well as provide cognitive evaluation of their food situation (e.g., being worried about running out of food). Questions asking about actual (as opposed to perceived) food conditions still require explicit evaluation, introducing potential confounding variables between the objective food situation and the response.

While such measures provide insight into attitudes toward food availability, they do not necessarily reflect the same underlying variable as objective measures of food security in non-human models. Although this variable might be characterized as perceived food security for humans, it could reflect other (implicit or explicit) attitudes toward food. Implicit and explicit attitudes are not always consistent within individuals (Rydell \& McConnell 2006), including in the context of food and eating (Hoefling \& Strack 2008). Further, respondents' explicit evaluations of their food conditions are not always consistent with objective measures: A recent USDA study found that experiential measures of food security did not 
match nutrition-based measures. Over two thirds of households that were undernourished in calories did not report experiencing food insecurity; conversely, around a third of households classified as being adequately nourished reported experiencing mild food insecurity (Broussard \& Tandon 2016).

Potential discrepancies between quantitative and qualitative measures suggest that theories proposing food security as a causal factor must define their concept of food security and ensure that this is consistent with the evidence relied upon. Even so, A\&G's model does not provide a satisfactory explanation for the positive association between human food insecurity and obesity, which applies only to women in high-income countries (Nettle et al. 2017). This is problematic for A\&G's hypothesis, which is based on general psychological mechanisms and thus should be generally applicable. If food insecurity increases behaviors that lead to overeating, the hypothesis predicts that an association between food insecurity and obesity should be observed generally.

To evaluate the relevance of A\&G's model to human obesity, we can refer to data that are more directly comparable with food security as it is defined in non-human contexts, such as their model of foraging behavior. For example, when food security is assessed by calories available per capita, global trends indicate that food insecurity is decreasing, with daily caloric supply increasing steadily in all regions since 1969 (Alexandratos \& Bruinsma, 2012). This is not consistent with A\&G's hypothesis, which predicts that as food insecurity decreases, obesity should also fall. However, human obesity has been rising rapidly at the same time as food insecurity (when quantified in a manner analogous to that used by $A \& G$ ) is decreasing. 
Just as food security in A\&G's model may not correspond to the notion of food security in human populations, the assumption that the simple foraging behavior represented in the model is applicable to humans may not be warranted. Humans possess a combination of relatively large brains, social structures, food-sharing behaviors, and complex foraging techniques not observed in other species (Hill et al. 2011; Schuppli et al. 2016), which may reflect changes in brain metabolism and diet hypothesized to have arisen with the evolution of the genus Homo. (Leonard \& Robertson 1994). Therefore, extrapolation from animal models of foraging to human behavior needs explicit justification, which A\&G do not provide.

Today's foodscape differs dramatically from the food environment to which human foraging behaviors were, presumably, well adapted. Consequently, food-related human behavior today may diverge even further from patterns that can be explained by non-human models. For example, humans, in common with other species, can discriminate the energy density of foods that occur naturally (i.e., in unprocessed form) in the environment (Gibson \& Wardle 2003). This ability is important for successful foraging (Brunstrom \& Cheon 2018). Foods occurring naturally during early human evolution were typically low in energy density $(<1.75 \mathrm{kcal} / \mathrm{g})$. However in modern, industrialized food environments, common processed foods can be more than twice as energy dense; and when it comes to evaluating foods with an energy density that would have been unusually high historically, human ability to differentiate breaks down (Brunstrom et al. 2018). This suggests that while evolutionary thinking and recourse to psychological mechanisms might be helpful in explaining 
associations between the food environment and patterns of obesity, characteristics specific to humans and human foodscapes may need to be taken into account.

While A\&G's hypothesis may be useful for explaining foraging behaviors in passerines, the authors' extrapolation from an animal model to human food behavior is neither justified theoretically nor well supported by the patterns of food supply and obesity observed in human populations. To make progress in revealing potential relationships between food security and obesity, it will be necessary to determine precisely what the standard food security measures in humans represent, taking into account psychological processes alongside socioeconomic factors and characteristics of the food environment.

$<\mathrm{C}$-Text ends $>$

\section{$<$ RFT $>$ References [Ursula Pool] [UP]}

$<$ refs $>$

Alexandratos, N. \& Bruisma, J. (2012). World agriculture towards 2030/2050: The 2012 revision. ESA Working paper No. 12-03. Rome, FAO.

Broussard, N. H. \& Tandon, S. (2016) Food insecurity measures: Experience-based versus nutrition-based evidence from India, Bangladesh and Ethiopia, Economic Research Report 220. U.S. Department of Agriculture, Economic Research Service. [UP]

Brunstrom, J. M. \& Cheon, B. K. (2018) Do humans still forage in an obesogenic environment? Mechanisms and implications for weight maintenance. Physiology \& Behavior 193(Part B):261-67. https://doi.org/10.1016/j.physbeh.2018.02.038_ [UP] 
Brunstrom, J. M., Drake, A. C. L., Forde, C.G. \& Rogers, P. J. (2018) Undervalued and ignored: Are humans poorly adapted to energy-dense foods? Appetite 120:589-95.

\section{[UP]}

Gibson, E. L. \& Wardle, J. (2003) Energy density predicts preferences for fruit and vegetables in 4-year-old children. Appetite 41:97-98_[UP]

Hill, K. R., Walker, R. S., Bozicevic, M., Eder, J., Headland, T., Hewlett, B., Hurtado, M. A., Marlowe, F., Wiessner, P. \& Wood, B. (2011) Co-residence patterns in huntergatherer societies show unique human social structure. Science 11:1286-89. [UP]

Hoefling, A. \& Strack, F. (2008) The tempting effect of forbidden foods. High calorie content evokes conflicting implicit and explicit evaluations in restrained eaters. Appetite 51:681-89. https://doi.org/10.1016/j.appet.2008.06.004 [UP]

Leonard, W. R. \& Robertson, M. L. (1994) Evolutionary perspectives on human nutrition: The influence of brain and body size on diet and metabolism. American Journal of Human BiologyBiol 6:77-88. doi:10.1002/ajhb.1310060111 [UP]

Nettle, D., Andrews, C. \& Bateson, M (2017) Food insecurity as a driver of obesity in humans: The insurance hypothesis. Behavioral and Brain Sciences 40:E105. https://doi.org/10.1017/S0140525X16000947. [UP]

Nord, M., Andrews, M. \& Carlson, S. (2009). Household food security in the United States, 2008 (Economic Research Report 83). U.S. Department of Agriculture. Available at: https://www.ers.usda.gov/webdocs/publications/err83/10987_err83_1_.pdf [UP]

Popkin, B. M. \& Gordon-Larsen, P. (2004) The nutrition transition: worldwide obesity dynamics and their determinants. International Journal of Obesity 28:S2-S9. doi:10.1038/sj.ijo.0802804 [UP] 
Rydell, R. J. \& McConnell, A. R. (2006) Understanding implicit and explicit attitude change: A systems reasoning analysis. Journal of Personality and Social Psychology 91:9951008. http://doi:10.1037/0022-3514.91.6.995 [UP]

Schuppli, C., Graber, S. M., Isler, K. \& van Schaik, C. P. (2016) Life history, cognition and the evolution of complex foraging niches. Journal of Human Evolution 92:91-100. [UP]

UN Food and Agriculture Organisation (FAO), IFAD, UNICEF, WFP \& WHO (2017). The state of food security and nutrition in the world 2017. Building resilience for peace and food security. FAO. [UP] 